\section{The Emotional Intelligence of the Principal is Essential in the Leadership of a Functional School}

\author{
Keshni Bipath
}

\begin{abstract}
Two neighboring schools, consisting of the same external and internal environment, the same political, environmental, social and technological environments and educators who are similarly qualified and experienced - yet perform as if they are in two different worlds. One schools rates as functional (80\% - 100\% in the SCE) while the other school is rated as dysfunctional (0\%-40\% in the SCE). The SCE is the common examination written by all learners in public schools after a 12 year schooling experience (Grade R-12). The principals of both schools possess teaching diplomas and have the similar number of years of experience. It is clear that the principals in these two schools possess totally different personalities. The functional school principal is highly emotionally intelligent whilst the dysfunctional school principal hardly possesses any of the competencies in emotional intelligence. The purpose of this paper is to explore whether the emotional intelligence of the principals impact on the performance of these two schools?
\end{abstract}

Keywords: Emotional Intelligence, Leadership, Functional Schools, Dysfunctional Areas, Senior Certificate Examination, South Africa

\section{Introduction}

IT WAS the best of times, it was the worst of times, it was the age of wisdom, it was the age of foolishness, it was the epoch of belief, it was the epoch of incredulity, it was the season of Light, it was the season of Darkness, it was the spring of hope, it was the winter of despair, we had everything before us, we had nothing before us, we were all going direct to Heaven, we were all going direct the other way - in short, the period was so far like the present period, that some of its noisiest authorities insisted on its being received, for good or for evil, in the superlative degree of comparisononly" (Dickens, 1981, p. 1).

Analogous to Dickens's "Tale of two cities", this research is about a tale of two schools. Both these schools are situated in the same geographic location; however the functioning of these schools is as different as if they were in two different cities. The above quotation introduces two paradoxical and contradictory types of schools. The first type of school is a dysfunctional school. Dysfunctional schools are schools in a state of chaos

(Shipengrower\& Conway, 1998, p.xv). Chaos is a word used to describe a system that is unstable (ibid.). "The current turbulent environment of education requires a response so different from the traditional approach of diagnose-planimplement-evaluate that only the term chaos expresses the dynamism, fluidity, and extraordinary complexity that contemporary educational administrators face" (Shipengrower \& Conway, 1998, p.xvi). The second school is a school portraying order. I refer to this school as a functional school. The Sunday Times (Pretorius, 2000, p.24) refers to functional schools as "best of the best". A school that is rated "best of the best" not only produces the best results in the Senior Certificate Examination (SCE) but also provides a quality education. The former Education Minister Kader Asmal (ibid.) said the main objective of publishing the "best of the best schools" list was "to place the performance of all schools in the public domain so as to encourage communities, school governing bodies, parents, teachers and learners to play a more active role in turning around schools that are performing poorly". He said the list was also aimed at building "a sense of pride and ownership in schools that performed well" (Pretorius, 2000, p.25).

In 2003, the functional school in this research project scored a $100 \%$ pass-rate in the Senior Certificate Examination (SCE), while the dysfunctional school scored $57,35 \%$. Both these schools are located in an informal settlement of Ivory Park, a township North East of Midrand in the Gauteng province of South Africa. Schools situated in low socioeconomic settings face greater problems, states Thrupp (1999, p.3). He argues that these schools, often located in areas with high levels of unemployment and crime, as well as poor housing and health conditions, are required to take on a huge caring role in addition to their academic one in order for learners to achieve academically. Many of these schools are under-funded and inadequately staffed compared to schools in wealthier areas. Despite the evident honour and dignity of most staff and students, low-socioeconomic schools face extremely tough problems: they are the sharp end of what Kazol (cited in Thrupp, 1999, p.3) has called "savage inequalities".

\section{Background to the Research Problem}

Dysfunctional schools felt that they were victims of an oppressive system, which paralysed them and made them indifferent and dependent (Christie, 1998, p.290). Feeling unfairly treated by the system and unable to perform their tasks, they masked their anxieties, fears and dissatisfactions by blaming others and performing their tasks at a minimum level.

Christie (1998, p.291) claims that the breakdown of management and leadership within schools is an important part of their dysfunction. 
Townsend (1999, p.342) accords the dysfunctionality to the previously racially skewed distribution of educational resources. The teachers best qualified under apartheid still are generally white, and still continue to teach in white suburban schools. Recently appointed black teachers who occupy newly created management posts such as head of department and deputy principal at Black township and rural schools lack the experience of their White, Coloured and Indian colleagues. Christie (1998, p.291) highlights the necessity for establishing proper and effective management systems and structures with clear procedures and clear lines of authority, powers, responsibility and accountability to improve the culture of teaching and learning in a dysfunctional school.

It is important to recognise that school culture is not the cause of the problems inherent in dysfunctional schools. It is the development of a school culture, which is inimical to learning and teaching. It is also necessary to recognise that learning and teaching were of a doubtful quality particularly in black schools, under apartheid, well before the notion of a breakdown emerged (Kallaway, 1984, p.2). According to Kallaway (1984, p. 162) "Bantu Education signifies education for subservience and cultural domination precisely by imposing outmoded tribal customs, languages and government onto unwilling blacks".

In an evaluation of the education of blacks from 1910 to 1953, the Eiselen Commission found that there were certain weaknesses in the prevailing system of education. These were as follows: "educational programmes were not part of a socioeconomic development plan; there was no active participation of the Blacks in their own control; inspection and supervision of schools were inadequate; the school life of the pupil was too short; the general orientation of schooling was too academic; teachers were not sufficiently involved in the broader planning of general development schemes for the Blacks" (Behr, 1984, p. 179).

A disconcerting feature in black education has been the high teacher pupil ratio. Furthermore, no less than $17,6 \%$ of primary school teachers were unqualified (Behr, 1984, p.191). If learning and teaching were of a doubtful quality in black schools, under apartheid, well before the notion of a breakdown emerged (Kallaway, 1984, p.2), the restoration of a culture of learning and teaching, means, in fact, its transformation (Christie, 1998, p.286). In the wake of the transformation efforts researchers looked intensely at effective schools to identify elements that set them apart (Shipengrover and Conway, 1996, p.xiii). The current turbulent environment in dysfunctional schools can be transformed by analysing how the successful implementation of formal school improvement practices compares with the components considered to compose a total quality management system (Shipengrover and Conway, 1996, p.1).

\section{Rationale and Problem Statement}

This paper argues that if "savage inequalities" was the issue facing low socio-economic schools, why are some secondary schools situated in the rural areas achieving high pass rates in the SCE. Over the past few years, the transformation of dysfunctional schools has been highlighted. Magau (2004, p.8) states that she has found it fascinating to see some of our star matric students coming from townships and rural areas. All of a sudden it became clear that excellence was achievable by black students, even in the most desperate environments. To observe students with distinctions coming from homes that in some instances did not have electricity was inspiring. It is about how historical inequalities, which were keeping our economy hostage, were profoundly refo-cused to meet the needs of all our people and place our country and people in the global arena (Magau, 2004: 8).

After a thorough qualitative study which consisted of observation, document analysis and interviews over a period of four weeks in each of the two schools, the paper aims to explore whether emotional intelligence of the principals was the determining factor on the school being functional or not. The principal of the functional school had realised how the historical inequalities were keeping his school as a hostage and he profoundly took all the necessary action to transform his school into a functional school. He had "emotional intelligence". Researchers have confirmed that emotional intelligence not only distinguishes outstanding leaders or principals, but can also be linked to strong performance, in this case, functional schools. The emotional intelligence of the leader consists of competencies such as self-awareness; self-regulation; motivation; empathy and social skills. It would be foolish to assert that good old fashioned intelligence and technical ability are not important ingredients in strong leadership. But the recipe of good leadership would not be complete without emotional intelligence. Once it was thought that the components of emotional intelligence were "nice to have" in leaders. But now we know that, for the sake of performance, these are ingredients that "leaders" need to have (Goleman, 1998, p.94). The paper displays that emotional intelligence in leaders is essential for the transformation of dysfunctional schools into functional schools.

\section{Research Design and Methods}

In order to achieve the aim of the research, a qualitative method using the techniques of observation, document analysis and interviews were carried out at each school. Interviews were carried out 
with the principals, the School Governing Bodies (SGB), groups of educators as well as the Representative Council of Learners (RCL) of the two schools. The perceptions of all stakeholders regarding the strength and weaknesses of the two schools; document analysis, as well as observations in the two schools over the first two weeks of every term for a school year serves to elucidate the relationship between emotional intelligence and functionality /dysfunctionality of the two schools being researched. Triangulation was achieved by analysing the schools, budget statements, minutes of management meetings, vision, mission and school development plans. The emotional intelligence of the principal in the functional school was compared to the emotional intelligence of the principal in the dysfunctional school in the same low socio-economic area.

\section{What is Emotional Intelligence?}

Goleman (1997b) provides a useful definition of emotional intelligence, which is about:

\section{Table 1: The Competency Framework for}

\section{Emotional Intelligence}

SELF AWARENESS Emotional self-awareness

Accurate self-assessment Self-confidence

SELF-MANAGEMENT Emotional self-control Transparency Adaptability

Achievement orientation Initiative Optimism
Knowing what you are feeling and being able to handle those feelings without having them swamp you; being able to motivate yourself to get jobs done, being creative and performing at your peak; and sensing what others are feeling and handling relationships effectively.

In order to ensure effective people leadership, leaders need to be effective. 'Effective leaders are alike in one crucial way: they all have a high degree of emotional intelligence', states Goleman (1998a: 94). In recent years the notion of 'emotional intelligence' had been seen as critically important to effective leadership and 'superior performance'. According to Goleman (1998b) and Goleman, et al. (2002), the leading exponent of the concept, the higher an individual rises in an organisation the more important emotional intelligence (EQ) becomes. Goleman's model of emotional intelligence includes 18 competencies, in four clusters. The competency framework for emotional intelligence is depicted as follows:

\section{SOCIAL AWARENESS}

Empathy

Organisational awareness Service

orientation

\section{RELATIONSHIP MANAGEMENT}

Developing others

Inspirational leadership

Change catalyst

Influence

Conflict management

Teamwork /Collaboration 
Each of the above competencies was observed and gauged according to the functionality or dysfunctionality of the school.

\section{Self Awareness and Functionality/ Dysfunctionality of the Schools}

The first quadrant, self awareness concerns knowing one's internal states, preferences, resources, and intuitions (Goleman, et al. 2002). How would this quadrant relate to functionality of schools? The functional school was clean and neat and the pass rate of $100 \%$ was shown with pride on all notice boards. The vision and mission of the school was pasted in every class. Educators were in the classes teaching and learners seemed enthusiastic. Books were on the table and learning was taking place. During my four weeks of observation, it was amazing that the school ran like clockwork. The principal walked around the school at all intervals and watched the learners as they entered classes. He was visible and knew every learner's name. The learners respected him and greeted when they saw him. Educators performed ground duties during breaks and when it was time to get back to the class, there was quick movement to class and silence when lessons began.

As far as emotional awareness (recognising one's emotions and their effects) was concerned, observations and interviews with the learners proved that the functional school principal had a presence and the learners loved and respected him because he carried himself with dignity and decorum desired of a role model. He knew his strengths and limits and possessed the self onfidence and esteem of a leader. He was prepared to visit schools of excellence and learn how to change his school. He realised the enormous pressure that matriculants faced and had parents educated about the support required. Due to the fact that the school was situated in a township area and his learners were from squatter camps which had only one huge room, his school was open during the late hours for the learners to study in a conducive environment. He was confident of his leadership skills and applied for a National Leadership Award and won. He was an inspiration not only for the learners, but also his educators. His educators spoke of him in the highest of term during interviews. "He is a leader that carries us with him in his success" said an educator. Although he was slightly built, his stepped out with the power and charisma that led to the success of his school.

The dysfunctional school was just down the road from this school. Noise, broken window panes, broken desks and chairs strewn on the verandahs, a dirty school ground and holes in the fences were the features of this school. Street vendors were camping on the schools grounds and were allowed to sell their food and drinks to learners during school hours. Educators were not in classes and learners sat in classroom doing nothing. Many learners came to school at $11 \mathrm{am}$ and went home at $1 \mathrm{pm}$. no textbooks and exercise books were on the desks and many of the learners were drugged. In an RCL interview, learners said that "they had nothing to do in school because educators did not come to teach. The principal only walked around once in the year. They did not ven have text books although they were in matric".

The cowering posture and the smoking of cigarettes at all odd hours rendered the dysfunctional principal not worthy of his post and the learners were even prepared to run away during lunch times because they were fully aware that he had no control of the educators or the learners. He showed his weaknesses openly. In the minutes of the staff meeting it is noted that only a few educators attend meetings and most of them apologise and leave early. He cannot get his entire staff together to ensure that they understand and implement new policies by the government. During an interview with the principal, he said that the educators are all against him and he cannot reprimand them because they are a team against him. He did not possess the knowledge that he had the power as a principal to lead and manage. His role was not clear to him. He was unaware that he was responsible for the learners' education, not the educators' whims and fancies.

\section{Self Management and the Functionality/Dysfunctionality of Schools}

Goleman, et al (2002) defines self-management as managing ones' internal states, impulses, and resources. The self-management cluster contains six competencies emotional self-control (keeping disruptive emotions and impulses in check); transparency (maintaining integrity, acting congruently with one's values); adaptability (flexibility in handling change); achievement (striving to improve or meeting a standard of excellence; initiative (readiness to act on opportunities) and optimism (persistence in pursuing goals despite obstacles and setbacks).

The functional school principal manages himself in such a way that he says that "I have to be abnormal in a normal situation. I arrive at school at $6 \mathrm{am}$ and leave at $11 \mathrm{pm}$ while the matriculants are studying. I drive past the school at all odd hours. The people here think that I am mad but I need to do this for the sake of the learners in my school. I want them to do well". His school's budget statement and monthly reports are pasted on the notice boards for all stakeholders to view. 
The parents are invited to meetings on a Sunday after church services because he is well aware that they will not be present at any other time due to work, travel and circumstances that townships face. During my observations at meetings, this principal is knowledgeable on all educational policies and his confidences gives rise to his optimism in getting stakeholders to buy in on new creative initiatives. He uses any opportunity to achieve the vision he has for his school. His vision is "achieving excellence".

On the other hand the principal of the dysfunctional school is highly nervous and worried all the time. During his interview he refuses to be tape recorded. He says that "when two elephants fight, the ground shudders". He blames the previous principal for allowing chaos to reign. He says that the learners wanted "that principal out and now they want me out". During my observations, he only arrived at 11:00 and left for a doctor's appointment at 13:00 almost every day. Before a staff meeting that was called up by him a week earlier, he cancelled the meeting and went home. He also holds meetings during schools hours and learners go home while educators are at a meeting. The dysfunctional school principal shows no initiative to change the culture of the school. He says that I have a development plan that educators will not follow. When looking at the plan, it is noticed that the name of the district office is printed boldly on the front and his plan is written over many pages in tiny writing with single spacing. It is evident that this plan was merely drawn for the sake of handing in to the district office. He gets upset when asked for the schools budget statement and does not even know that he has to write reports about the use of finances in his school.

\section{Social-awareness and Functionality and Dysfunctionalty of Schools}

Social-awareness refers to how people handle relationships and awareness of others' feelings, needs and concerns (Goleman, et al.2002). The socialawareness cluster contains three competencies namely empathy (sensing others' feelings and perspectives, and taking interest in their concerns); organisational-awareness (reading a group's emotional currents and power relationships) and service orientation (anticipating, recognising, and meeting customers' needs). The functional school principal is able to sense others' feelings and perspectives, and taking interest in their concerns. Knowing that his learners are from such poverty stricken backgrounds, he allows them to study at school. The safety and concerns of the parents are laid to rest by employing additional security guards late at night. One or two educators are always on duty when learners are studying.
Educators are incentives for providing extra classes in the morning or evenings and are rewarded for achieving distinctions in their subjects. He shows organisational-awareness by reading a group's emotional currents and power relationships. When educators in the lower standards complained that they were not being rewarded because they did not teach matrics, he gave them an opportunity to be part of the team by assisting with studying and homework after hours. He scores highly on service orientation and recognises and meets learners' needs.

None of the three competencies are shown by the dysfunctional school principal. This principal lacks being a change catalyst. He does not recognize the need for change. He likes to keep things the way they are without getting involved in any change initiatives. He does not have the confidence or the will to actively implement change. When educators arrive late and leave early, he is afraid of confronting them because he, himself, arrives late and leaves early. He is afraid of confrontation and does not understand the labour policy concerning misconduct. The noise factor in his school is so high; he surely knows that learners are creating a din when teachers are not in classes. He does not move out of the office to walk around and observe what is going on in his school. The huge holes cut in the fence are escape routes for learners. The principal shows no concern when children jump through and roam the streets. The one hole on the fence is close to his office, yet he has not reprimanded the learners for escaping. For the entire 4 weeks during my observation, the holes were gaping, yet no one took responsibility for the mending of the fence. He is not prepared to change the culture of demotivation and destruction in his school.

\section{Relationship Management and Functionality and Dysfunctionality of Schools}

Goleman, et al. (2002) define relationship management as the skill or adeptness at inducing desirable responses in others. The relationship management cluster contains six competencies: developing others (sensing others' development needs and bolstering their abilities); inspirational leadership (inspiring and guiding individuals and groups) ; change catalyst (initiating or managing change); influence (wielding effective tactics for persuasion); conflict management (negotiating and resolving disagreements) and teamwork and collaboration (working with others towards shared goals and creating group synergy in pursuing collective goal).

In this last quadrant, the functional school principal rates teamwork and collaboration as the reason 
for his $100 \%$ pass rate. He is able to get his entire staff working with the similar enthusiasm and excitement towards a vision of excellence at his school. Each year during the third term holidays, he gets the educators to draw up the developmental plan for the next year. They talk about problems and improvements. He says that "we will not allow a problem to repeat itself. We only work with people who are willing to work hard. There is no place for shirkers in my school". The educators are willing to come to school because "they have their worksheets typed by the secretaries and on their desks the next week". I observed the principal duplicating worksheets for educators because the secretaries were "very busy". The principal says in one of the interviews, "I delegate my responsibilities to my management staff because they are also principals. They are part of me. I help out when necessary". In the management staff meeting minutes it is evident that constructive criticism takes place when final decisions are needed to be made. The educators that were interviewed all mentioned that their principal was indeed an inspiration to them.

The principal of the dysfunctional school avoids conflict at all costs, even at the expense of the teaching and learning in the school. He is fully aware of the educators who are not teaching, yet he has not called them in to reprimand them or warn them about the code of conduct for an educator. Educators come and go from school whenever they like and this principal is afraid of calling them in the next day. $\mathrm{He}$ is not confident about his task as a principal. He says in the interviews that most teachers take 10 minutes before they reach their classes to teach, yet he has not addressed this issue at a staff meeting. Out of the 60 educators in the school, only 15 attended the staff meetings which are called up urgently. This principal has never called in the others or even sent a note to them to explain their absence. There is a culture of disrespect and a "don't care attitude" that exists between the educators and the principal. He has not even asked for assistance from the district about this problem.

When interviewed, this principal clearly says that "lack of teamwork, low attendance at classes, punctuality, bad attitude, lack of commitment and unpre-paredness are some of the factors that hinder the progress of the school". The principal does not collaborate with others to draw up plans and policies. He expects buy-in from the staff when they have not been part of drawing up the vision, mission or school policy. During the interviews with the educators, most don't even know what the vision or mission statement of the school is.

This principal prefers working alone without coordinating with others. He does this to avoid confrontation to resolve conflicts with other team members. He states that his SMT was never supportive in implementing the budget and the plans. He cannot take criticism constructively and hence thought that all members of his SMT were personally attacking him when they were bringing his attention to other factors in implementing improvement plans.

\section{Emotional Intelligence and Functionality/Dysfunctionality of Schools}

The article proves that emotional intelligence of the principals in the two schools created the difference in the performance of the two schools. The self awareness displayed by the principal in the functional school showed an understanding of his moral purpose as a principal to the learners in his school. His self awareness that he is no longer trapped as a victim of apartheid and he can make a difference in his school was the essential in the first two quadrants in the emotional intelligence framework that the researcher observed. He took the initiatitive and visited schools of excellence to learn what they were doing right. He was influential and coerced his staff to work collaboratively to achieve excellent results. These two quadrants greatly enhanced the other two quadrants in the emotional intelligence framework, namely social awareness and relationship management. Due to the functional school's principal being aware of himself as well as his surroundings, he was able to focus on relationships with his learners and staff and got them to collaborate and work as a winning team in the achievement of a functional school.

On the other hand, the principal of the dysfunctional school lacked the competencies of self awareness and self management which led to his failure of being socially aware of his rights and responsibilities as leader in his school. He could not get his staff to work collaboratively as a team towards a common vision.

This tale of two schools echoes with the importance of training principals in leadership skills. Fortunately, emotional intelligence can be learned. This process takes time and, most of all, commitment. Induction courses for principals should have "Emotional Intelligence Competency Development" as an essential module. Fortunately the ACE school leadership programme designed as a licence for school principals in South Africa contains a module that teaches principals how to develop emotional intelligence. The benefits that come from having a well developed emotional intelligence, both for the individual and for the organisation, make it worth the effort (Goleman, 1998, p. 102). After all it is the future generation that will benefit from training all educational leaders on emotional intelligence. 


\section{Conclusion}

With acknowledgement to Dickens's "Tale of two cities", it was best of emotional intelligence, it was the worst of emotional intelligence, it was the school of functionality, it was the school of dysfunctional-ity, it was the epoch of optimism, it was the epoch of pessimism, it was the season of teamwork and collaboration, it was the season of absenteeism and defiance, it was the spring of hope in the functional school, it was the winter of despair in the dysfunctional school, the functional school had everything before them, the dysfunctional school had nothing before them, the learners in the functional school were all going direct to University, the learners in the dysfunctional school were all going direct the other way - in short, the period was so far like the present period, that some of its noisiest government departments insisted on its being received, for good or for evil, in the superlative degree of comparison only.

\section{References}

Behr, A. L. (1984). New perspectives in South African Education: A review of education in South Africa (1652-1894). Durban: Butterworth.

Christie, P. (1998). Schools as (dis) organizations: the 'breakdown ofthe culture of learning and teaching' in South African schools. Cambridge Journal of education, 28(3).

Dickens, C. (1981). A tale of two cities. Cape Town: Maskew Miller

Goleman, D. (1997b) 'Beyond IQ: developing the leadership competence of emotional intelligence', paper presented at the 2 . international competency conference, London, October

Goleman, D. (1998a) Working with emotional intelligence, Bloomsbury Publishing, London

Goleman, D (1998b) "What makes a leader?" Harvard Business Review, Vol.76, pp. 93-104.

Goleman, D; Boyatzis, R and Makee, A. (2002), Primal Leadership: Realising the Power of Emotional Intelligence, Harvard Business School Press, Boston, Massachusetts.

Kallaway, P. (ed) (1984) Apartheid and Education: The education of Black South Africans. Johannesburg: Ravan Press.

Magau, N. (2004). Looking back 10 years, what stands out? Looking ahead 2014, what should we shape and what should the role of intellectuals be? GDE (2004) Proceedings ofthe fifth educationally speaking conference, Johannesburg: GDE.

Pretorius, C. (2000). The best and worst of our schools - Asmal ranks South Africa's 5500 high schools - and we publish the full list. Sunday Times, 16 January 2000:2.
Shipengrower, J.A. \& Conway, J.A. (1998). Expecting excellence: creating order out of chaos in a school district. Thousand Oaks: Corwin Press.

Thrupp, M. (1999). Schools Making a difference: Let's be realistic. Philadelphia: Open University Press

Townsend, T; Clarke, P. \& Ainscow, M. (Eds) (1999). Third millennium schools: A world of difference in effectiveness and improvement, Amsterdam: Swets \& Zeitlinger 